\title{
Bicyclo[4.2.0]octa-1,3,5-trien-3-yl-dimethyl((E)-styryl) -silane
}

\author{
Konstantin S. Levchenko ${ }^{1, *}$, Konstantin A. Chudov ${ }^{1}$, Dmitri Yu. Demin ${ }^{2}$, Pavel S. Shmelin ${ }^{2}$ and \\ Evgeny P. Grebennikov ${ }^{2}$ \\ 1 RTU MIREA-Russian Technological University, 78 Vernadsky Avenue, Moscow 119571, Russia; \\ k4udov@gmail.com \\ 2 JSC «Technomash», 4 Ivana Franko Str., Moscow 121108, Russia; demindd@mail.ru (D.Y.D.); \\ shmelin@cnititm.ru (P.S.S.); grebennikov@cnititm.ru (E.P.G.) \\ * Correspondence: k.s.levchenko@gmail.com; Tel.: +7-985-188-6215
}

Received: 2 December 2019; Accepted: 19 December 2019; Published: 23 December 2019

\begin{abstract}
Bicyclo[4.2.0]octa-1,3,5-trien-3-yl-dimethyl-((E)-styryl)-silane was synthesized via three stage synthesis starting from benzocyclobutene and (2-bromo-vinyl)-benzene. The structure of the product was determined using ${ }^{1} \mathrm{H}$ - and ${ }^{13} \mathrm{C}-\mathrm{NMR}$ and HRMS.
\end{abstract}

Keywords: benzocyclobutene; Grignard reaction; bicyclo[4.2.0]octa-1,3,5-trien-3-yl-dimethyl-((E)styryl)-silane; (2-bromo-vinyl)-benzene

\section{Introduction}

Silicon organic compounds are widely used as intermediates in various syntheses and as target substances in industrial chemistry. Polysiloxanes and polysilanes are known as coupling agents for enhanced adhesion [1,2]. They increase mechanical and dielectric properties of composites [3], improve dispersion of pigments and industrial minerals, provide crosslinking, immobilize catalysts, and bind biomaterials [4].

Many companies are developing silane- and siloxane-based photo or thermo curable materials for electronics. For example, Polyset company (https://www.polyset.com) created a family of novel siloxane-based monomers and oligomers that are especially attractive for such applications as microelectronics, photonics, composites, coatings, and adhesives. These novel materials bear reactive functional groups consisting of cyclohexyl epoxy, glycidyl ether, vinyl ether, and acrylate moieties as well as combinations of these group. Dow chemicals (www.dow.com) presents a line of composite materials (CYCLOTENE ${ }^{\mathrm{TM}}$ ) with divinylsiloxane (DVS) and benzocyclobutene (BCB) based component as photoresists and thermosets (Divinyl siloxane bis-benzocyclobutene, DVS-BCB). In recent years, many new articles have appeared devoted to the development of hybrid silanes or siloxanes and BCB containing monomers [5-10]. The polymerization of these compounds occurs due to the presence of acrylate, silocyclobutene groups, alkenes (including vinyl, styryl, and allyl groups), etc. Crosslinking of the polymers provides a benzocyclobutene fragment capable of thermal opening $(t$ $>200{ }^{\circ} \mathrm{C}$ ) with the formation of active o-xylylenes. Several polymerization mechanisms are known: Interactions of o-xylylenes with active alkenes ([4+2] cycloaddition, (Scheme 1A)) or by itself with the formation of a polydiphenylethylene or cyclooctane structures [11]. Photocurable DVS-BCB composites include [12] photoactive bisazide compounds that are capable of forming aziridines (Scheme 1B) under UV-irradiation. BCB crosslinked polymers have high values of glass transition temperatures and thermal stability $[5,6,13]$.

In this short note we present a synthesis of a new bicyclo[4.2.0]octa-1,3,5-trien-3-yl-dimethyl-((E)-styryl)-silane (BCB-KS) that include 
benzocyclobuten-3-yl and vinylbenzene moieties. It may be of interest in the creation of photo and thermopolymerizable composites and used in synthetic processes as an intermediate compound.

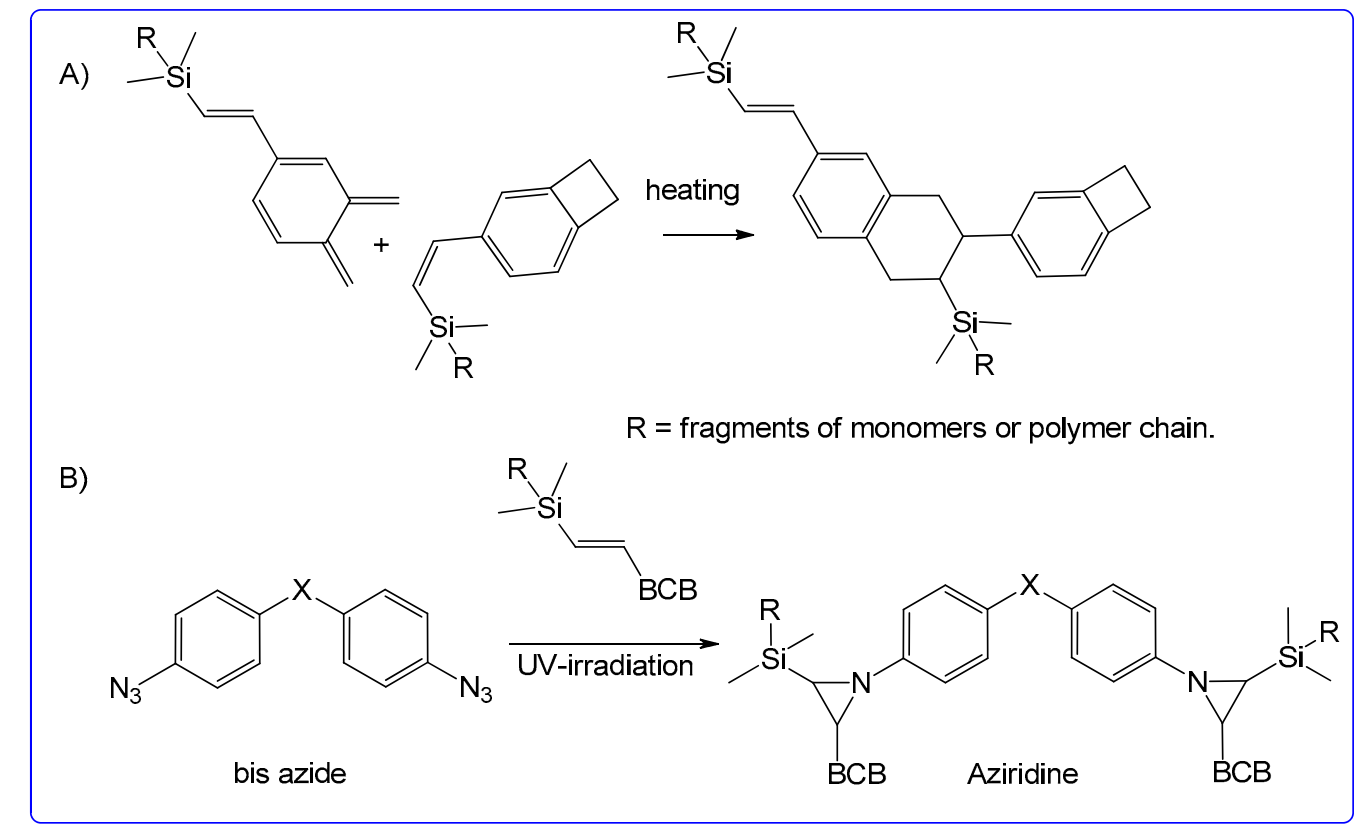

Scheme 1. Scheme of photo and thermo polymerization of DVS-BCB and analogs in absence (A) or presence $(\mathbf{B})$ of bisazide photocoupling agent.

\section{Results and Discussion}

Synthesis of the title compound is presented on Scheme 2 and include a three stage process from (2-bromovinyl)benzene and benzocyclobutene. In the first step, (2-bromovinyl)benzene was added to mixture of dichlorodimethylsilane and magnesium in tetrahydrofuran (THF) at $25-30{ }^{\circ} \mathrm{C}$. The resulting dimethylchloro((E)-styryl)silane was purified by vacuum distillation. The byproducts in this reaction are 1,4-diphenylbutadiene and styrene.

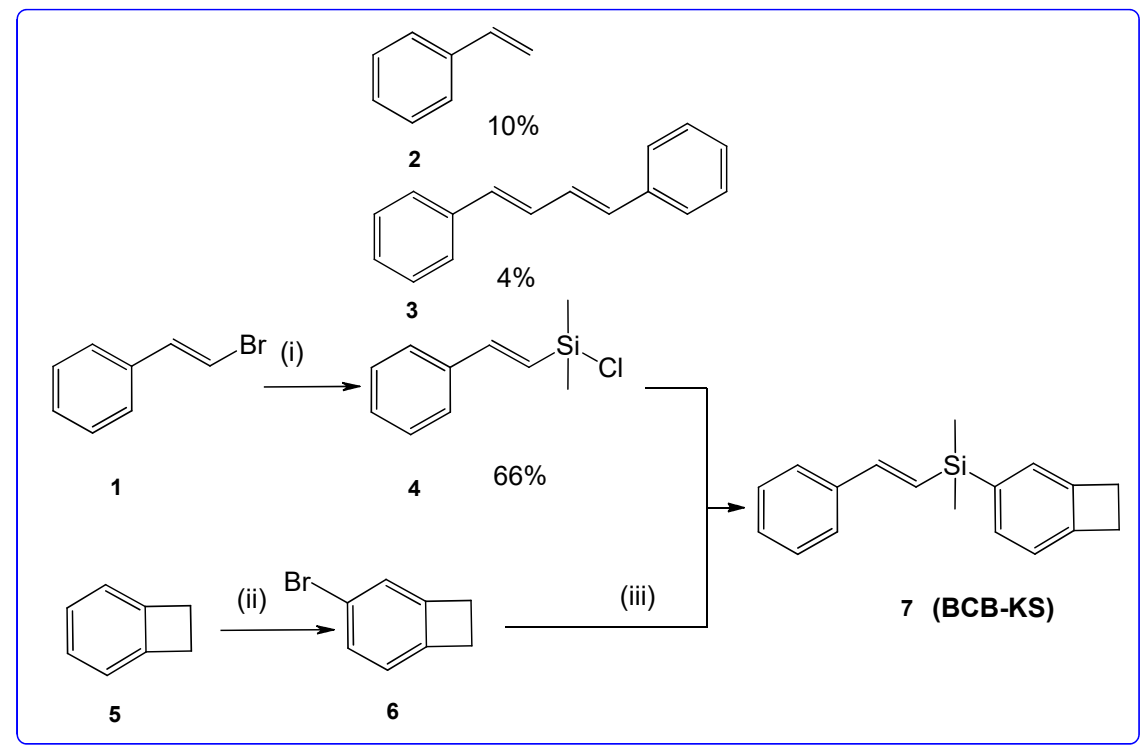

Scheme 2. Synthesis of bicyclo[4.2.0]octa-1,3,5-trien-3-yl-dimethyl-((E)-styryl)-silane (BCB-KS). (i) $\mathrm{Mg}, \mathrm{Me}_{2} \mathrm{SiCl}_{2} \mathrm{THF}, 25-30{ }^{\circ} \mathrm{C}$; (ii) $\mathrm{Br}_{2}, \mathrm{H}_{2} \mathrm{O},-10-20{ }^{\circ} \mathrm{C}, 20 \mathrm{~h}$; and (iii) $\mathrm{Mg}$, THF, 4, 25-30 ${ }^{\circ} \mathrm{C}$, after r.t., overnight. 
Dimethylchloro((E)-styryl)silane can also be obtained from phenylacetylene and dimethylchlorosilane [14,15]. Upon receipt in this way, the target product is contaminated with dimethylchloro(1-phenylvinyl)silane.

Dimethylchloro((E)-styryl)silane reacts with benzocyclobuten-3-yl magnesium bromide to produce the desired benzocyclobuten-3-yl-dimethyl((E)-styryl)silane (BCB-KS) as colorless fusible solid with $65.6 \%$ yield.

All compounds were characterized by ${ }^{1} \mathrm{H},{ }^{13} \mathrm{C}$ NMR, and HRMS analysis. NMR data of known compounds were compared with previously published data [16-18]. These NMR, HRMS and FTIR data of compounds can be found in the Supplementary Materials.

Signals of the carbon atoms of the $-\mathrm{CH}_{2}-\mathrm{CH}_{2}-$ of the compound 7 (BCB-KS) cyclobutene ring were found in the ${ }^{13} \mathrm{C}$ NMR spectra at 29.83 and $29.95 \mathrm{ppm}$, hydrogen atoms were detected as slightly broadened singlet at $3.21 \mathrm{ppm}$. Double bond of 7 gives two signals in ${ }^{1} \mathrm{H}$ NMR spectra at 7.07 and 6.71 ppm with high value of $J$-constants $(19.1 \mathrm{~Hz})$, which confirms its trans orientation. $\mathrm{Two}^{\mathrm{C}} \mathrm{CH}_{3}$ groups of $-\mathrm{Si}\left(\mathrm{CH}_{3}\right)_{2}$ are detected in ${ }^{1} \mathrm{H}$ NMR and ${ }^{13} \mathrm{C}$ NMR spectra at 0.52 (s) and -2.26 , respectively. Aromatic hydrogens were indicated at 7.11-7.50 ppm. In ${ }^{13} \mathrm{C}$ NMR spectrum there were found high-intensity signals at 126.50 and $128.52 \mathrm{ppm}$ related to pairs of symmetric carbons of the phenyl group. Six signals $(145.06,132.25,128.10,127.72,127.59$, and 122.01) of tertiary carbon atoms and four signals of quaternary carbon atoms $(147.22,145.63,138.25$, and 136.59) were found.

\section{Materials and Methods}

NMR spectra were registered using a Bruker AM-300 or a Bruker Avance 600 spectrometer (Bruker Corporation, Billerica, MA, USA) in $\mathrm{CDCl}_{3}$. Mass spectra were obtained on a Varian MAT $\mathrm{CH}-6$ instrument (Varian, Inc, Palo Alto, CA, USA) using a direct inlet system; the ionization energy was $70 \mathrm{eV}$; the acceleration voltage was $1.75 \mathrm{kV}$. The reaction mixtures were analyzed and the purity of all products was checked by TLC on Merck Silica gel 60 F254 UV-254 plates. Dimethyldichlorosilane was purchased from abcr $\mathrm{GmbH}$, Karlsruhe, Germany. Magnesium powder was purchased from Sigma-Aldrich, Co., USA. Bromine, solvents were purchase from «Base No. 1 «Chimreactivov», Staraya Kupavna, Russia. Other of the reagents were produced from JSC «Technomash, Russia.

\subsection{4-Bromobenzocyclobutene (6)}

Benzocyclobutene $(23.7 \mathrm{~g}, 22.8 \mathrm{mmol})$ was dispersed in $240 \mathrm{~mL}$ of water at room temperature. After cooling with ice water, $11.7 \mathrm{~mL}$ of bromine $\left(-10-5^{\circ} \mathrm{C}\right)$ was added dropwise. After complete of addition, the ice water bath was removed and the reaction mixture was warmed to room temperature and stirred overnight. The reaction was monitored by TLC until the starting benzocyclobutene disappeared. The mixture was diluted with $50 \mathrm{~mL}$ of $n$-hexane and sodium sulfite $(3 \mathrm{~g}, 23.8 \mathrm{mmol})$ was added. Upon completion of the addition, the mixture was stirred at room temperature for $30 \mathrm{~min}$. The mixture discolored. Then, the separated organic layer was dried over anhydrous sodium sulfate, filtered to remove the drying agent, and concentrated under reduced pressure to obtain 4-bromobicyclo [4.2.0] octa-1 (6), 2,4-triene. After distillation at $110-114{ }^{\circ} \mathrm{C}(15 \mathrm{~mm}$ of $\mathrm{Hg}), 28-30 \mathrm{~g}$ was obtained as a colorless liquid. ${ }^{1} \mathrm{H}$ NMR $\left(300 \mathrm{MHz}, \mathrm{CDCl}_{3}\right) \delta 7.40(\mathrm{~d}, J=7.8 \mathrm{~Hz}, 1 \mathrm{H}), 7.26(\mathrm{~s}, 1 \mathrm{H}), 6.99(\mathrm{~d}, J=7.8 \mathrm{~Hz}$, $1 \mathrm{H})$, and $3.31-3.10(\mathrm{~m}, 4 \mathrm{H})$.

\subsection{Dimethylchloro((E)-styryl)silane (4)}

(2-Bromovinyl)benzene $(18.3 \mathrm{~g}, 100 \mathrm{mmol})$ was added to a mixture of $\mathrm{Mg}(2.4 \mathrm{~g}, 100 \mathrm{mmol})$ and $12.9 \mathrm{~g}(100 \mathrm{mmol})$ of dimethyldichlorosilane in $50 \mathrm{~mL}$ of dry THF under Ar atmosphere and cooling $(\mathrm{t}$ $=20-35^{\circ} \mathrm{C}$ ). The next day, THF was evaporated. The residue was extracted with dry hexane several times. The extracts were combined and evaporated. Distillation under vacuum ( $2.25 \mathrm{~mm} \mathrm{of} \mathrm{Hg}$ ) gives three fractions. The first fraction contains styrene, the second was collected at $90-130{ }^{\circ} \mathrm{C}$ and contains the main product. Higher boiling fractions contain 1,4-diphenylbutadiene. After repeated distillation, 
dimethylchloro((E)-styryl)silane was obtained. Yield 66\%. ${ }^{1} \mathrm{H}$ NMR $\left(300 \mathrm{MHz}, \mathrm{CDCl}_{3}\right) \delta 7.54-7.29(\mathrm{~m}$, $5 \mathrm{H}), 7.15(\mathrm{~d}, J=19.1 \mathrm{~Hz}, 1 \mathrm{H}), 6.57(\mathrm{~d}, J=3.1 \mathrm{~Hz}, 1 \mathrm{H}), 0.66(\mathrm{~s}, 6 \mathrm{H})$.

\subsection{Benzocyclobuten-3-yldimethyl((E)-styryl)silane (7) (BCB-KS)}

4-Bromobenzocyclobutene $(5.49 \mathrm{~g}, 0.03 \mathrm{~mol})$ was added over $1 \mathrm{~h}$ to a mixture of dimethylchloro (E)-styrylsilane $(5.88 \mathrm{~g}, 0.03 \mathrm{~mol})$ and $\mathrm{Mg}(760 \mathrm{mg}, 0.032 \mathrm{~mol})$ in $25 \mathrm{~mL}$ of THF at $25-32{ }^{\circ} \mathrm{C}$. After addition, the mixture was left to stand overnight. The next day, water was added to the mixture. The resulting solution was extracted with methylene chloride. After evaporation, the oil is dissolved in hexane and passed through $1 \mathrm{~cm}^{3}$ of silica gel and evaporated again. The residue was distilled in vacuum at a temperature of $167-169^{\circ} \mathrm{C}(1.5 \mathrm{~mm}$ of $\mathrm{Hg})$. A clear, viscous liquid $(5.2 \mathrm{~g}, 65.6 \%)$ was obtained, which solidifies in the refrigerator. $\mathrm{Mp} 32^{\circ} \mathrm{C}$. $1 \mathrm{H} \mathrm{NMR}\left(300 \mathrm{MHz}, \mathrm{CDCl}_{3}\right)$ 7.60-7.52 $(\mathrm{m}, 3 \mathrm{H})$, $7.48-7.32(\mathrm{~m}, 4 \mathrm{H}), 7.20(\mathrm{~d}, J=7.2 \mathrm{~Hz}, 1 \mathrm{H}), 7.07(\mathrm{~d}, J=19.1 \mathrm{~Hz}, 1 \mathrm{H}), 6.71(\mathrm{~d}, J=19.1 \mathrm{~Hz}, 1 \mathrm{H}), 3.31(\mathrm{~s}, 4 \mathrm{H})$, and $0.52(\mathrm{~s}, 6 \mathrm{H}) .{ }^{13} \mathrm{C}$ NMR $\left(126 \mathrm{MHz}, \mathrm{CDCl}_{3}\right) \delta 147.22,145.63,145.06,138.25,136.59,132.25,128.52$, $128.10,127.72,127.59,126.50,122.01,29.95,29.83$, and -2.26 . HRMS, found: 265.1404 , calculated [M + H]: 265.1407.

\section{Conclusions}

New benzocyclobuten-3-yldimethyl((E)-styryl)silane (BCB-KS) was obtained via three stage synthesis starting from benzocyclobutene and (2-bromovinyl)benzene with good yields. Obtained product can be useful for development of new polymerizable composite materials with good thermal stability and dielectric properties or used in synthetic processes as an intermediate.

Supplementary Materials: Supplementary data to this article can be found online. These data include MOL file, ${ }^{1} \mathrm{H},{ }^{13} \mathrm{C}$ NMR, HRMS, FTIR data of the title compound.

Author Contributions: Synthesis, K.S.L. and K.A.C.; NMR data analysis, D.Y.D. and P.S.S.; Writing-original draft preparation, K.S.L.; Writing-review and editing, K.S.L. and P.S.S.; Supervision and project administration, E.P.G. All authors have read and agreed to the published version of the manuscript.

Funding: The work was financially supported by a grant from the Ministry of Science and Higher Education of the Russian Federation (Agreement on granting a subsidy from the Ministry of Science and Higher Education of the Russian Federation dated June 14, 2019, № 075-15-2019-1273 (inner № 14.577.21.0273), Unique identifier-RFMEFI57717X0273.

Conflicts of Interest: The authors declare no conflict of interest. The funders had no role in the design of the study; in the collection, analyses, or interpretation of data; in the writing of the manuscript, or in the decision to publish the results.

\section{References}

1. Pantoja, M.; Abenojar, J.; Martínez, M.A.; Velasco, F. Silane pretreatment of electrogalvanized steels: Effect on adhesive properties. Int. J. Adhes. Adhes. 2016, 65, 54-62. [CrossRef]

2. Chen, B.; Lu, Z.; Meng, H.; Chen, Y.; Yang, L.; Zhang, H.; Xie, H.; Chen, C. Effectiveness of pre-silanization in improving bond performance of universal adhesives or self-adhesive resin cements to silica-based ceramics: Chemical and in vitro evidences. Dent. Mater. 2019, 35, 543-553. [CrossRef] [PubMed]

3. Babanzadeh, S.; Mahjoub, A.R.; Mehdipour-Ataei, S. Novel soluble thermally stable silane-containing aromatic polyimides with reduced dielectric constant. Polym. Degrad. Stab. 2010, 95, 2492-2498. [CrossRef]

4. Gelest. Industrial Silanes for Adhesives \& Sealants, Coatings and Composites. Available online: https: //www.gelest.com/wp-content/uploads/Industrial_Silanes.pdf (accessed on 20 December 2019).

5. Levchenko, K.S.; Chudov, K.A.; Adamov, G.E.; Poroshin, N.O.; Shmelin, P.S.; Grebennikov, E.P.; Parshikov, Y.G. Photocurable and Thermosetting Polymer Materials on the Basis of Benzocyclobutene and Its Derivatives for Electronics. Russ. J. Gen. Chem. 2018, 88, 2793-2812. [CrossRef]

6. Levchenko, K.S.; Chudov, K.A.; Demin, D.Y.; Adamov, G.E.; Poroshin, N.O.; Shmelin, P.S.; Grebennikov, E.P.; Chvalun, S.N.; Zubov, V.P. Synthesis of photo and thermosetting monomers and polymers based on benzocyclobutene. Russ. Chem. Bull. 2019, 68, 1321-1342. [CrossRef] 
7. Hu, H.; Liu, L.; Li, Z.; Zhao, C.; Huang, Y.; Chang, G.; Yang, J. Benzocyclobutene/vinylphenyl-introduced polycarbosilanes with low dielectric constant, high temperature performance and photopatternability. Polymer 2015, 66, 58-66. [CrossRef]

8. Huanga, Y.; Zhanga, S.; Hua, H.; Weia, X.; Yub, H.; Yanga, J. Synthesis of poly(silmethylene)s via ring-opening polymerization of benzocyclobutene functionalized disilacyclobutene and their low-dielectric and thermal properties. Polym. Adv. Technol. 2017, 28, 1480-1488. [CrossRef]

9. Yang, J.; Liu, S.; Zhu, F.; Huang, Y.; Li, B.; Zhang, L. New Polymers Derived from 4-Vinylsilylbenzocyclobutene Monomer with Good Thermal Stability, Excellent Film-Forming Property, and Low-Dielectric Constant. J. Polym. Sci. Part A Polym. Chem. 2011, 49, 381-391. [CrossRef]

10. Yang, L.; Cao, K.; Huang, Y.; Chang, G.; Zhu, F.; Yang, J. Synthesis and properties of cross-linkable polysiloxane via incorporating benzocyclobutene. High Perform. Polym. 2014, 26, 463-469. [CrossRef]

11. So, Y.-H.; Hahn, S.F.; Li, Y.; Reinhard, M.T. Styrene 4-Vinylbenzocyclobutene Copolymer for Microelectronic Applications. J. Polym. Sci. Part A Polym. Chem. 2008, 46, 2799-2806. [CrossRef]

12. Ohba, K. Overview of Photo-definable Benzocyelobutene. Polym. Photopolym. Sci. Technol. 2002, 15, $177-182$. [CrossRef]

13. Kirchhoff, R.A.; Bruza, K.J. Polymers from Benzocyclobutenes. In High Performance Polymers; Hergenrother, P.M., Ed.; Advances in Polymer Science; Springer: Berlin/Heidelberg, Germany, 1994; Volume 117, pp. 1-66. [CrossRef]

14. Pandarus, V.; Ciriminna, R.; Gingras, G.; Béland, F.; Kaliaguine, S.; Pagliaro, M. Waste-free and efficient hydrosilylation of olefins. Green Chem. 2019, 21, 129-140. [CrossRef]

15. Brook, M.A.; Neuy, A. The beta-effect: Changing the ligands on silicon. J. Org. Chem. 1990, 55, 3609-3616. [CrossRef]

16. Roth, M.; Ahles, M.; Gawrisch, C.; Schwalm, T.; Schmechel, R.; Melzer, C.; von Seggern, H.; Rehahn, M. Rodlike Tetracene Derivatives. Chem. Eur. J. 2017, 23, 13445-13454. [CrossRef] [PubMed]

17. Zhong, Z.; Wang, Z.-Y.; Ni, S.-F.; Dang, L.; Lee, H.K.; Peng, X.-S.; Wong, H.N.C. Ligand-Free Iron-Catalyzed Carbon $\left(\mathrm{sp}^{2}\right)-$ Carbon $\left(\mathrm{sp}^{2}\right)$ Oxidative Homo-Coupling of Alkenyllithiums. Org. Lett. 2019, 21, 700-704. [CrossRef] [PubMed]

18. Chauhan, B.P.S.; Sarkar, A. Functionalized vinylsilanes via highly efficient and recyclable Pt-nanoparticle catalysed hydrosilylation of alkynes. Dalton Trans. 2017, 46, 8709-8715. [CrossRef] [PubMed]

(C) 2019 by the authors. Licensee MDPI, Basel, Switzerland. This article is an open access article distributed under the terms and conditions of the Creative Commons Attribution (CC BY) license (http://creativecommons.org/licenses/by/4.0/). 